\title{
Characteristics of Carbon Films Deposited by Magnetron Sputtering
}

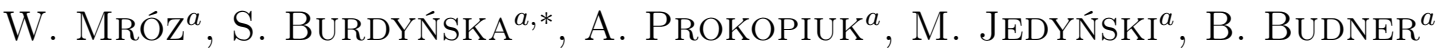 \\ AND M.L. KORWIN-PAWLOWSKI ${ }^{b}$ \\ ${ }^{a}$ Military University of Technology, Institute of Optoelectronics \\ S. Kaliskiego 2, 00-908 Warsaw, Poland \\ ${ }^{b}$ Université du Québec en Outaouais, Département d'informatique et d'ingénierie \\ 101, rue Saint-Jean-Bosco, Gatineau, Québec J8X 3X7, Canada
}

\begin{abstract}
Carbon thin films are often called in the literature, "diamond-like carbon" films. They consist of two basic allotropic forms of carbon, which are graphite and diamond. Carbon atoms with $s p^{2}$ bonds form after deposition of a graphite-like phase. Atoms with $s p^{3}$ bonds form a diamond-like phase. Diamond-like crystallites are built into a graphite-like phase matrix. In this paper there are presented experimental results of deposition of carbon films by the magnetron sputtering method and the results of analysis of the surface and phase structures of the deposited films. The amorphous carbon films were deposited from graphite targets on 316L steel substrates. The films were deposited at room temperature, in vacuum. The deposition time was $3 \mathrm{~h}$; the depositions were conducted at two different distances between the substrate and the magnetron target.
\end{abstract}

PACS numbers:

\section{Introduction}

Diamond-like carbon (DLC) films are of interest to researchers because of their mechanical and tribological properties. Experimental results proved that the films are characterized with low friction coefficient, high hardness and durability. Those properties depend on the method of deposition as well as on the physical process conditions during the deposition itself [1-4].

Carbon films of the DLC type are a mixture of solid phases - the hard diamond-like phase with $s p^{3}$ bonds and the softer graphite-like phase with $s p^{2}$ bonds. Graphite-like films have good tribological properties and can act as a lubricant.

By adjusting the ratio of $s p^{2}$ to $s p^{3}$ bonds in the deposited films one can obtain the desired functional properties of the films. The composition ratio of the two phases in the resulting film depends on the method of deposition and on the physical process parameters during deposition.

At present, the main problem of the deposition of DLC films is their relatively poor adhesion to the substrate and the existence of internal stress within the films, especially at higher thicknesses, which leads to delaminating from the substrate and to cracks in the films $[5,6]$.

DLC films can be deposited using various meth-

\footnotetext{
* corresponding author; e-mail: sburdynska@wat.edu.pl
}

ods. The most common methods are electron cyclotron resonance plasma assisted chemical vacuum deposition (ECR-CVD) [7, 8], DC and RF enhanced chemical vacuum deposition (PECVD) [9, 10], pulse laser ablation $[11,12]$ and magnetron sputtering $[13,14]$.

The objective of the conducted experiments of depositing carbon films using the magnetron sputtering method was to determine the influence of deposition conditions on the phase and surface structure of the films. The analysis of the deposited films was done based on results of atomic force microscopy (AFM) and Fourier transform infrared spectroscopy (FTIR) investigations.

\section{Experimental}

Carbon thin films were deposited from graphite targets on $316 \mathrm{~L}$ steel substrates using a $3^{\prime}$ toroidal magnetron system of Kurt J. Lesker Inc. with $13.56 \mathrm{MHz}$ RF power of $50 \mathrm{~W}$. The pressure in the process chamber during the experiments was $7 \times 10^{-3}$ Torr. The deposition was conducted at room temperature and the time of deposition was $3 \mathrm{~h}$. The substrate to target distance was $(50 \pm 1) \mathrm{mm}$ and $(100 \pm 5) \mathrm{mm}$.

\section{Results}

In Fig. 1 there are presented images of the topometric AFM scans of the films deposited on substrates held at the distance of $(50 \pm 1) \mathrm{mm}$ from the target. The 
surface scan at lower magnification, showing an area of $10 \mu \mathrm{m} \times 10 \mu \mathrm{m}$, has the character of a smooth structure with narrow linear grooves in the film, propagating in various directions. In certain areas of the surface individual small islands of about $200 \mathrm{~nm}$ dimensions are visible. The scans done at higher magnifications of the areas of $2.5 \mu \mathrm{m} \times 2.5 \mu \mathrm{m}$ and $1 \mu \mathrm{m} \times 1 \mu \mathrm{m}$ reveal different surface structures with the presence of grains non-uniformly distributed on the surface. Even though the surface grains are not well evolved and the grains are not very high, the grain boundaries are clearly visible.
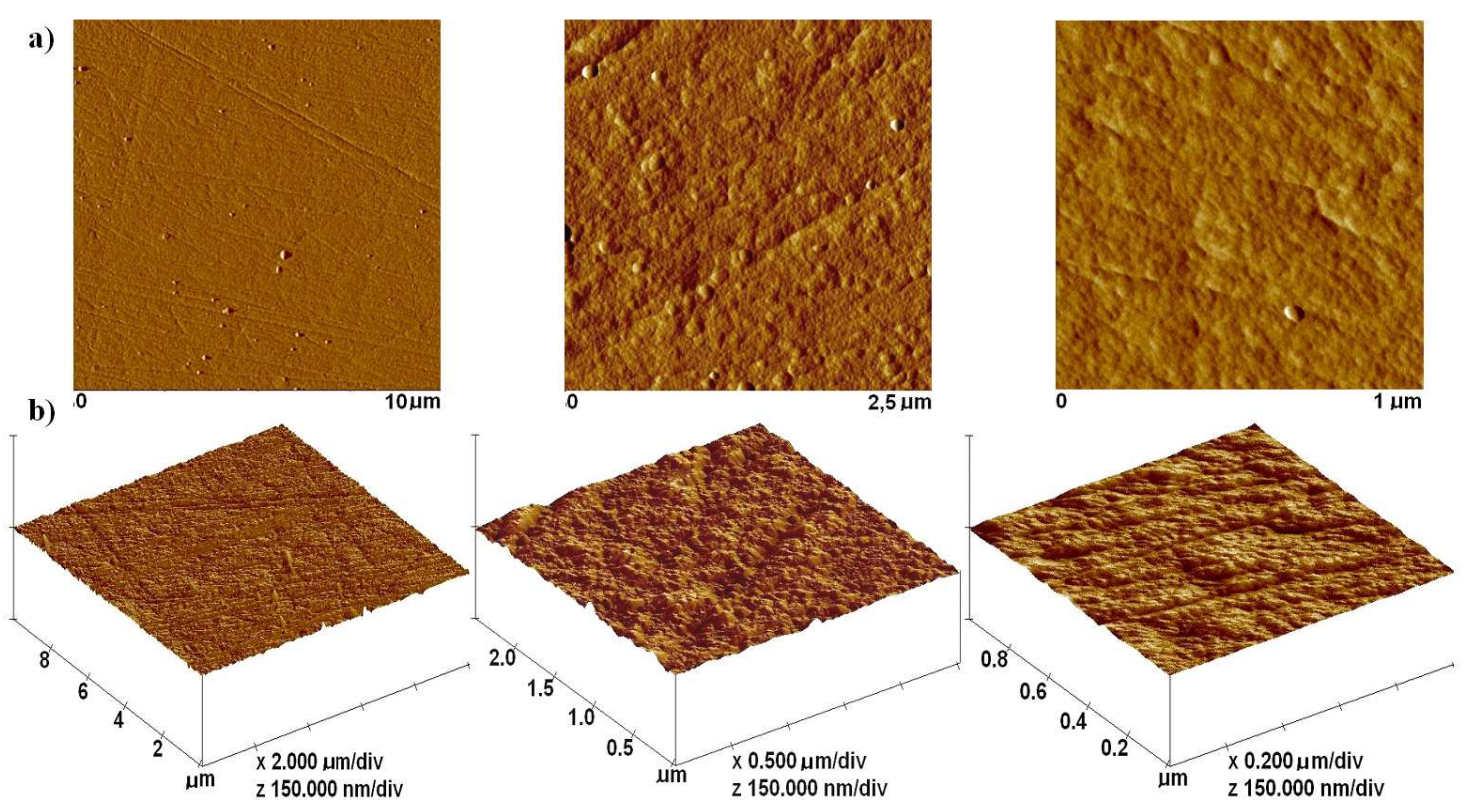

Fig. 1. Topometric AFM scans of carbon films deposited on 316L steel substrates. The substrate-target distance during deposition was $(50 \pm 1) \mathrm{mm}$ : (a) two-dimensional images, (b) three-dimensional images.
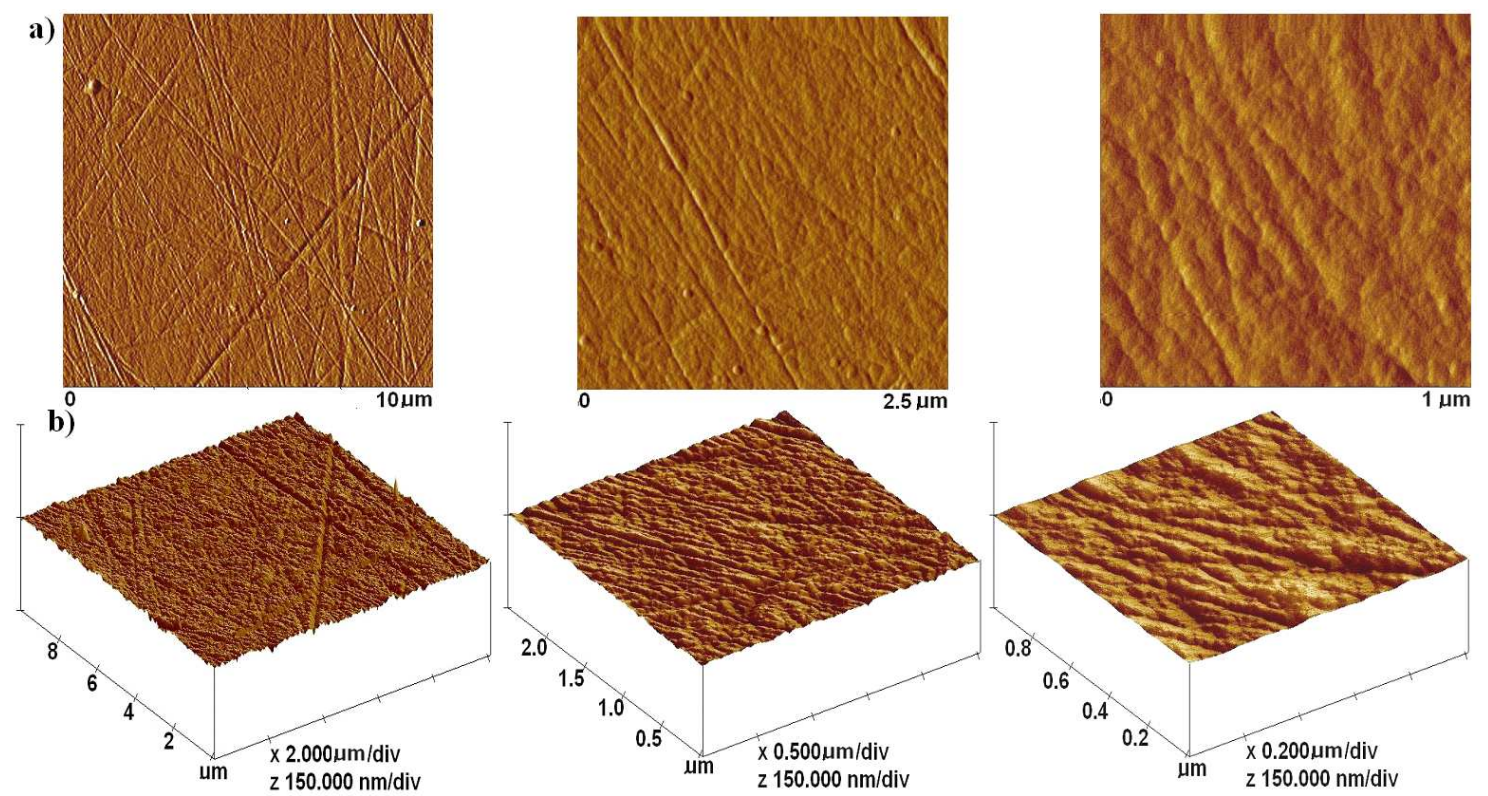

Fig. 2. Topometric AFM scans of carbon films deposited on 316L steel substrates. The substrate-target distance during deposition was $(100 \pm 1) \mathrm{mm}$ : (a) two-dimensional images, (b) three-dimensional images.

In Fig. 2 there are shown images of topometric AFM scans of carbon films deposited at the distance of $(100 \pm 5) \mathrm{mm}$ between the substrate and the target. The surface of the sample shown at $10 \mu \mathrm{m} /$ side magnification seems to be as smooth as was the case when the substrate to target distance was $50 \mathrm{~mm}$. As the result of 
increasing the substrate to target distance to $100 \mathrm{~mm}$, the height of the grains was reduced. A larger number of linear grooves on the surface going in various directions are also noticeable. The formation of those grooves is the result of the presence of scratches on the surface of the steel substrates. The higher number of surface grooves in the analysed samples confirms that the film is as expected thinner than that produced at the $50 \mathrm{~mm}$ substrate to target distance. Scans made at higher magnifications show differences of topography of the deposited films, but not as pronounced as was the case at $50 \mathrm{~mm}$ substrate to target distance.

In Fig. 3 there are presented absorption spectra of the deposited film using Fourier transform infrared spectroscopy.

The absorption spectrum of the film deposited at the substrate to target distance of $50 \mathrm{~mm}$ contains four bands. The peaks around $1460 \mathrm{~cm}^{-1}, 1740 \mathrm{~cm}^{-1}$ and $2860 \mathrm{~cm}^{-1}$ represent the vibration of the $s p^{3}$ bonds and indicate at the presence of diamond-like phase in the deposited film. The peak around $1600 \mathrm{~cm}^{-1}$ is characteristic of the $s p^{2}$ bond vibration and indicates the presence of the graphite-like phase. All registered bands are of low intensity, with the peak positioned around $2860 \mathrm{~cm}^{-1}$ having the highest intensity. The predominance of the bands corresponding to the $s p^{3}$ bonds indicates that the $s p^{3}$ phase is the majority phase in the film.

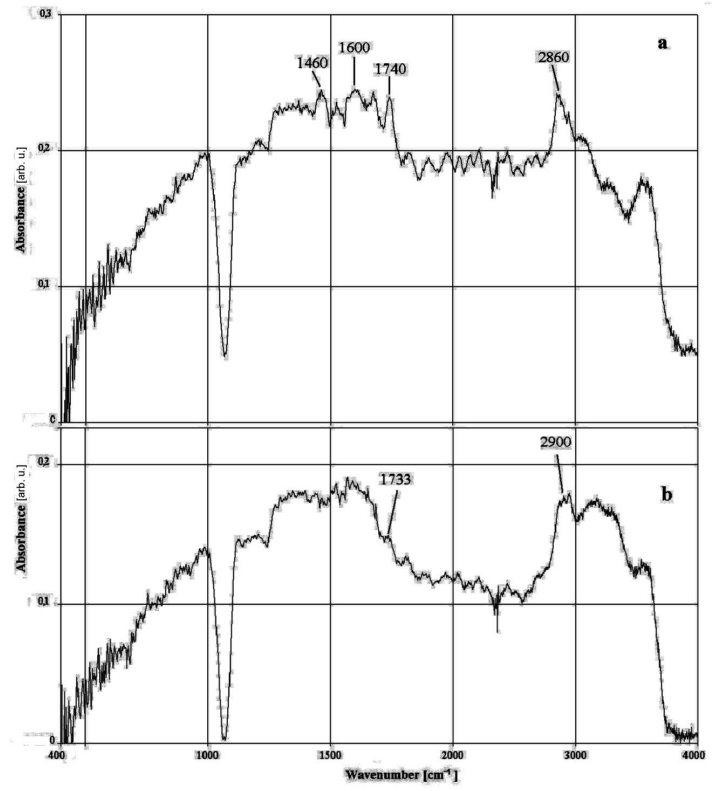

Fig. 3. FTIR spectra of carbon films deposited on 316L steel substrates at different substrate to target distances: (a) $(50 \pm 1) \mathrm{mm}$, (b) $(100 \pm 1) \mathrm{mm}$.

The spectrum of the film deposited at the substrate to target distance of $100 \mathrm{~mm}$ contains only two peaks: around $1733 \mathrm{~cm}^{-1}$ and around $2900 \mathrm{~cm}^{-1}$, both characteristic of the $s p^{3}$ bonds. This indicates the domination of the diamond-like phase in the deposited layer. However, those peaks have lower intensities when compared to the analogous peaks in the films deposited at the substrate to target distance of $50 \mathrm{~mm}$, confirming the already discussed thickness relationship of both films.

\section{Conclusions}

The deposited carbon films show smooth surface structures with characteristic linear grooves caused by surface scratches on the steel substrates on which they were deposited. The films deposited at the substrate to target distance of $50 \mathrm{~mm}$ are thicker than those deposited at the distance of $100 \mathrm{~mm}$. This is confirmed by the lower number of observables grooves and also by FTIR spectra having more peaks of higher intensity.

In the deposited films FTIR analysis proved the presence of the diamond-like phase at quantitatively comparable level with the graphite-like phase. Because the deposited films were of a few tens of nanometre thick, the FTIR measurements did not allow a more precise quantitative analysis of the $s p^{3} / s p^{2}$ phase ratio.

\section{Acknowledgments}

This work has been performed as part of the "Polish Artificial Heart" project for the years 2007-2011.

\section{References}

[1] L. Martina, D. Poetries, J. Vac. Sci. Technol. A 18 2619 (2000).

[2] C. Donnet, Surf. Coat. Technol. 100-101, 180 (1998).

[3] A. Grill, Diamond Relat. Mater. 8, 428 (1999).

[4] M. Śmietana, J. Szmidt, M.L. Korwin-Pawlowski, N. Miller, A.A. Elmustafa, Diamond Relat. Mater. 7-10, 1655 (2008).

[5] A. Erdemir, G.R. Fenske, J. Terry, P. Wilbur, Surf. Coat. Technol. 94-95, 525 (1997).

[6] M. Wang, X. Jiang, B. Stritzker, Thin Solid Films 197, 57 (1992).

[7] M. Diani, A. Mansu, L. Kubler, J.B. Bishoff, D. Bolmont, Diamond Relat. Mater. 3, 264 (1994).

[8] A. Bousetta, A. Lu, A. Bensaoula, A. Schultz, Appl. Phys. Lett. 65, 696 (1994).

[9] H. Gruger, D. Selbmann, E. Wolf, A. Leonhard, B. Arnold, Surf. Coat. Technol. 86-87, 409 (1996).

[10] S. Veprek, J. Weidemann, F. Glatz, J. Vac. Sci. Technol. A 13, 2914 (1995).

[11] J. Seth, R. Padiyath, S.V. Baba, Diamond Relat. Mater. 3, 210 (1994).

[12] M. Tabbal, P. Merel, S. Moisa, M. Chaker, A. Ricard, M. Moisan, Appl. Phys. Lett. 69, 698 (1996).

[13] T. Okada, S. Yamada, Y. Takeuchi, T. Wada, J. Appl. Phys. 78, 7416 (1995).

[14] R. Kaltofen, T. Sebald, G. Weise, Thin Solid Films 290-291, 112 (1996). 